\title{
Bıldırcın besisinde enzim ve avoparsin kullanımı
}

\author{
Sakine YAIÇIN ${ }^{1}$, Ilyas ONBAŞILAR ${ }^{2}$, Berrin GÜÇL Ü ${ }^{3}$ Ebru GÖNCÜOĞLU ${ }^{4}$
}

\begin{abstract}
: Ankara Universitesi. Veteriner Fakültcsi, Hayvan Besleme ve Beslenme Hastalıkları Anabilim Dalı. Ankara: ' Haccıtepe

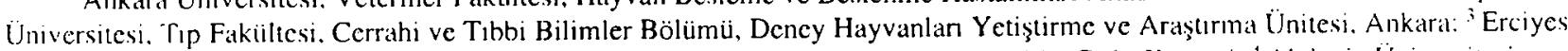
Universitesi, Veteriner Fakeiltesi, Hayvan Besleme ve Beslenme Hastallklan Anabilim Dall, Kayseri: ${ }^{4}$ Akdeniz Úniversitesi. Vetcriner Fakiiltesi. Hayvan Besleme ve Beslenme Hastalıkları Anabilim Dalı, Burdur
\end{abstract}

\begin{abstract}
Özet: Eiı araşurma, temelini arpa ve bự̆dayın oluşturduğu bıldırcın rasyonlarında enzim ve avoparsinin ayrı alyı ya da ikili kombinasyonları halinde kullanınlarının Japon bıldırcınlarında besi performansı, karkas randımanı ve bazı kan parameircleri ïzcrine ctkilerin belirlemek amaacılya yapılmıştır. Araştırmada toplam 328 adet günlïk Japon bıldırcm (Coturnix cotumin japonica) civeivi kullanılmıştır. Her birinde 82 civciv bulunan 1 kontrol, 3 deneme olmak ïzere 4 grup düzenlenmiştır. Gruplar ise 41 civeiv içeren iki tekrar grubuma ayrilmıștır. Dencme grupları rasyonlarına roxazym-G (100) ppm) ve avoparsin (15 ppm) ayrı ayri ya da ikili kombinasyonları şeklinde katılmıştır. Araştırma beş hafta sürdürülmuiştür. Araştırma sonunda gruplar arasında canlı alợ̆rlık. karkas randımanı ve kan serumunda total protein ve total lipid deģerleri bakımından istatistik açıdan bir farklılık göriilımemiş̧ır. Araş̧ırına siiresince bir $\mathrm{kg}$ canlı ağırlık artışı için tïketilen yem miktarı kontrol ile 1.. 2. ve 3. deneme gruplarında sırasiyla 3.1)6. 3.18. 3.199 ve $3.10 \mathrm{~kg}$ olarak hesaplanmışur. Sonuç olarak, rasyonlara roxazym-G ve/veya avoparsin ilavesinin bıldırcularda besi performaunsı. karkas randımanı ve kan serumu total protein ve total lipid degerleri üzerine önemli bir etkisinin olmadığg kanısılna varılmışur

Anahtur kelimeler: Avoparsin, besi performansı, bıldırcın, cnzim, kan parametreleri, karkas randımanı
\end{abstract}

\section{The usage of enzyme and avoparcin in quail fattening}

Summary: This study was carried out to determine the effects of the usage of enzyme and avoparcin alone or in combination on performance. carcass yield and some blood parameters of quails. A total of 328 daily Japancse quail chicks (Comumix comturnix japenical) were used in this experiment. They were divided into 4 groups ( 1 control and 3 treatment groups) cach containing 82 chicks. Each group was divided into 2 replicate groups containing 41 chicks. Experimental diets were supplemented with roxiryme-G ( $1(1)(1) \mathrm{ppm})$ and avoparcin $(15 \mathrm{ppm})$ alone or in combination. The experimental period lasted five weeks. Al the cnd of the study there were no statistically differences among the groups in live weight, carcass yield and total protein and total lipid values of hlood serum. Feed consumption per one $\mathrm{kg}$ live weight gain of control group and 1.. 2. and 3. treatment groups during trial were determined as $3.106 .3 .18,3.199$ and $3.10 \mathrm{~kg}$, respectively. It is concluded that the supplementation of roxazyme-G with or without avoparcin to the rations had no important effect on fattening performance, carcass yield and total protein and total lipid values of blond scrum of quails.

Key words: Avoparcin, blood parameters, carcass yield, enzyme, fattening performance

\section{Giriş}

Kanath rasyonlarında buğday ve arpa yüksck düzeylerde kullamıldığında ince bağırsak içeriğinin viskorilesi artmakıa ve dolayısıyla besin maddelerinin sindirimi ve emilimi azalmakta, altlık kalitesi ise olumsuz yönde etkilenmektcdir. Yüiksck düzeyde arpa veya çavdar kapsayan rasyonların civcivlerde besin madde emilimini aðaltuğı, buna karşılı antibiyotik ilavesinin bu olumsuzluğu gidererek, civciv performansını iyileştirdiği bildirilmiştir (11.16.31). Nişasta tabiatında olmayan polisakkaritleri parçalayan enzimler kanatlılarda sindirim içeriği viskozitesini azaltarak besin madde değerlendirilmesini arturmaktadırlar. Bundan dolayı enzimler bağırsak mikroflorasının bileşimini ve aktivitesini etkilemektedirler $(6,41)$.

Karakuş (24), arpa-buğday ağırlıklı broyler rasyonlarma roxazym-G (1000 ppm) ve/veya avoparsin (15 ppm) katılmasının kırk iki günlük araşırma süresince broylerlerin canlı ağırlık arışı, yemden yararlanma oranı, karaciğer ağırlığı ve kan serumunda total protein, total lipid ve total kolesterol değerlerini ctkilemediğini bildirmiş̧ir.

Vukic Vranjes ve Wenk (43) \%40 arpa kapsayan rasyonlara roxazym-G (200 ppm) ve/veya avoparsin (10 ppm) ilavesinin 7 günlük broyler civcivlerde 35 günlük deneme süresince etkilerini araştırnışlardır. RoxazynıG'nin, canlı ağırlık artışı, yemden yararlanma oranı, enerjinin metabolize olabilirliği, yag ve azotun değerlendirilmesi ve dışkının kuru madde miktarın olumlu yöncle eıkilediği saptanmıştır. Ayrıca, enzim kullanımının organizmada yağ ve enerji birikimini artırdığ fakat protein birikimi ile karkas randımanını etkilemediği kaydedilmiştir. Rasyonlara avoparsin ilavesinin ise enerjinin metabolize olabilirliğini ve yağ değerlendirilmesini art- 
urdığ fakat azol değerlendirilmesi, büyüme ve besin madde birikimi üzerine etkisinin olmadığı gözlenmiştir. Aynı araştırmada (43) enzim ve avoparsinin birlikte kullanılması durumunda ise civcivlerde büyüme, encrjinin metabolize olabilirliği ile yağ ve azot değerlendirilmesinin etkilenmediği kaydedilmiştir.

Bu araşurma, arpa-buğday ağırlıklı rasyonlarda roxazym-G ve avoparsinin ayrı ayrı ya da birlikte kullanımlarımın bildırcin besisinde besi performansı, karkas randımanı ve bazı kan parametreleri üzerine etkilcrini belirlemek amacıyla yapılmışır.

\section{Materyal ve Metot}

Araştırmada toplam 328 Japon bıldırcın (Coturnix coturnix juponica) civcivi kullanılmışur. Araştırma her birinde 82 civciv bulunan 1 kontrol ve 3 deneme grubu olmak ïzere 4 grup ile yürütiilmüştür. Civcivler her birunde 41 olacak şekilde 8 kafese rastgele dağtılmış ve böylece her grup için iki tekerrür grubu oluşturulmuştur.

Rasyonlar protein ve enerji duizeyleri eşit olacak şekilde hazırlannıştır. Kontrol grubu rasyonuna enzim ve antihiyotik katılmanıştır. Araştırmada enzim olarak roxazym-G*: antibiyotik olarak da avoparsin (roparsin)* ticari olarak tavsiyc edilen oranlarda kullanılmıştur. Roxazym-G ticari adlı preparat \%22 düzcyinde ksilanaz, alfa amilaz, selülaz, glukanaz, pektinaz enzimlerini, $\% 75$ lakto,$\% 2.5$ sitrik asit, $\% 0.5$ proteaz ve diğer enzimleri ihtiva etmektedir. Roparsin ticari adlı avoparsin preparat. Streptomyces candidcts adlı küfün yaptığı fernaantasyon sonucu üretilen bir metabolizma artığ Birinci, 2. ve 3. deneme grubu rasyonlarma smasiyla 15 ppm avoparsin, $1000 \mathrm{ppm}$ roxazym-G ve 15 ppm avoparsin+1000 ppm roxazym-G ilave edilmiştir. Araşturma rasyonunun bileşimi Tablo l'de gösterilmektedir

Hayvanlara yem ad lihitum verilmiştir. Ilk iki hafta kafeslerin ısıtıcılanı çalışurılmışur. Her bir kafesteki hayvanlar grup yemlemesine tabi tutulmuştur. Otomatik suluklar kullanılarak hayvanların önünde sürekli su bulunması sağlanmışırır. Gün ışı̆̆ı ile birlikte toplan 24 saat aydınlatma uygulanmıştır. Araştırma beş hafta sürdürülmüştür.

Araştırmada kullanılan yem maddelerinin ve rasyonların besin madde miktarları AOAC (5)'de bildirilen analiz metotlarına göre belirlenmiştir. Metaholize olabilir enerji düzeylerinin hesaplanmasında ise TSE (42)'nin öncrdiği formül kullanılmışıır.

Denemenin başlangıcında (0), 1, 2. 3, 4 ve 5 haftalık yaşta hayvanlar tek tek tartılarak canlı ağırlik ve canlı ağırlık artışları bulunmuştur. Her bir kafesteki ğrubun yem tüketimi haftalı olarak yapılan tartınlarla belirlenmiştir. Haftalık yemden yararlanma değerleri ise bir kilogram canlı ağırlık artışı için tüketilen yem nikları olarak hesaplanmıştır. Her bir gruptaki dişi ve crkck sayısı deneme sonunda tespit edilmiştir.

Tablo 1. Araştırma rasyonunun bileşimi.

Table 1. The composition of experimental ration.

\begin{tabular}{|c|c|c|c|}
\hline Yem maddesi & $\%$ & Kimyasal bileşim & \\
\hline Arpa & 25.00 & Kuru madde, \% & 89.8() \\
\hline Buğday & 30.00 & Ham protcin, $\%$ & 21.30 \\
\hline Misir & 1.71 & Ham yag. \% & 8.4() \\
\hline Tam yağglı soya & 8.00 & Ham sclüloz, \% & 4.96 \\
\hline Soya küispesi & 18.67 & Hàm kül, \% & 5.70 \\
\hline Bilkisel yad & 7.80 & Azotsuz öz madde. \% & 49.38 \\
\hline Ballak unu & $1 .(4)$ & Kalsiyum, \% & $(0.80$ \\
\hline Tavulk unu & 3.00 & Fosfor, $\%$ & 0.60 \\
\hline Et uns & 2.00 & Metabolize olabilir enerji, kcal/kg & 3057 \\
\hline Mermer tozu & 0.35 & & \\
\hline Dikalsiyum fosfat & 0.84 & & \\
\hline TuL & 0.30 & & \\
\hline Lirin & 0.09 & & \\
\hline Metiyonin & 0.24 & & \\
\hline Ön karışın* & 1.00 & & \\
\hline
\end{tabular}

*: Ön karışım bileşimi ( $8 \mathrm{~kg}$ içerisinde): $1 \mathrm{~kg}$ Rovimix 124-S Bilyem 95, $0.5 \mathrm{~kg}$ Remineral S Bilyem, $1 \mathrm{~kg}$ A latec. $1 \mathrm{~kg}$ kolin kloriir. $3 \mathrm{~kg}$ mermer tozu, $1 \mathrm{~kg}$ Myco Curb Dry.

Rovimix 124-S Bilyem 95: Bir kilogramında $12000000 \mathrm{IU}$ vitamin A, $3000(0) 0 \mathrm{lU}$ vitamin $\mathrm{D}_{3}$. $30 \mathrm{~g}$ vitamin E. $3 \mathrm{~g}$ vitamil $\mathrm{K}_{3} .2 \mathrm{~g}$ vitamin $\mathrm{B}_{1}, 5 \mathrm{~g}$ vitamin $\mathrm{B}_{2}, 40 \mathrm{~g}$ niasin, $12 \mathrm{~g}$ kalsiyum D-pantotenat, $5 \mathrm{~g}$ vitamin $\mathrm{B}_{6}, 15 \mathrm{mg}$ vitamin $\mathrm{B}_{12}, 750$ mg folik asit. 50 $\mathrm{mg} \mathrm{D}$ - biotin. $50 \mathrm{~g}$ vitamin $\mathrm{C}$ içcrmektedir.

Reınineral S Bilyem: Bir kilogramında $160 \mathrm{~g}$ mangane7, $120 \mathrm{~g}$ demir, $120 \mathrm{~g}$ çinko, $10 \mathrm{~g}$ bakır. $400 \mathrm{mg}$ kobalt. 2 g iyot. $300 \mathrm{mg}$ selenyum içcrmcktedir.

Avatec: Bir kilogramında $100 \mathrm{~g}$ lasalosid sodyum ihtiva eden antikoksidial premiksidir.

Myco Curb Dry: \%34.5 amonyum propyonat, \%30.5 propyonik asit, \%(0.25 sorbik asit. \%(0.5 fosforik asit. \%(1).1 BHA. \% $\% .25$

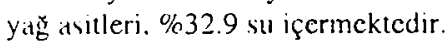

\footnotetext{
*: Roxazym-G ve roparsin, Roche Müstahzarları Sanayi A.Ş. 'den temin edilmiştir.
} 
Karkas randımanının bclirlenmesi için her gruptan alı crkek, altı dişi (her kafesten üç erkek, üç dişi) olmak ïzere on ikişer hayvan rastgele seçilerck tartılmıştır. Hayvanlar aç bırakılmadan kesime alınmış ve Islak yolmaya tabi tutulmuştur. Ayaklar kesilip iç organlar çıkartılarak karkaslar temizlenmiştir. Karkaslar $+4^{\circ} \mathrm{C}^{\prime}$ de 18 saat bekletildikten sonra tartılarak soguk karkas ağırlıklanı belirlenmiştir. Soğuk karkas ağırlığı kesim öncesi ağırlığa böllünerck soğuk karkas randımanı hesaplanmıştır.

Kesilen hayvanların kanları alınarak serumlarında biüret metodu ile total protein, Kunkel metodu ilc total lipid duizeyleri belirlenmiştir (18).

Canlı ağıılık, karkas ağırlığı, karkas randımanı ve kan scrumunda total protein ile total lipid degerleri bakımından gruplara ait istatistik hesaplamalar ve grupların ortalama değcrlcri arasındaki farklılıklann önemliliği için variyans analiz metodu, gruplar arasındaki farkın önem- lilik kontrolü için de Duncan testi uygulanmışur. Gruplar arasında ölüm oranı ve erkek-dişi bakımından bir farklılığın olup olmadığının kontrolünde Ki-kare testi kullanılmıştır (40). Istatistik analizler SPSS 10.00 (Inc., Chicago, IL, USA) programına görc yapılmıştır. Hayvanlar grup yemlemesine tabi tutulduğundan canlı ağırlık arışı, yem tüketimi ve yemden yararlanma oranı değerleri istatistik açıdan değerlendirilememiştir.

\section{Bulgular}

Araştırma süresince gruplardan elde edilen ortalama canlı ağırlık değerleri Tablo 2'de gösterilmektedir. Beş haftalık araştırma sonunda gruplar arasında canlı ağırlık bakımından istatistik açıdan önemli bir farklılık gözlenmemiştir. Gruplarda yem tüketini, canlı ağırlık artışı ve yemden yararlanma oranları Tablo 3 'de verilmektedir. Araştırma sonunda kesilen bıldırcınların karkas ağırlıklan ve karkas randimanları Tablo 4'de, kan serumunda total

Tablo 2. Grupliarda ortalama canlı ăğılıklar (g).

Table 2. Mean ive weights of groups (g).

\begin{tabular}{|c|c|c|c|c|c|c|c|c|c|c|c|c|c|}
\hline \multirow{3}{*}{$\begin{array}{l}\text { Yas } \\
\text { (haffa) }\end{array}$} & & & & \multicolumn{9}{|c|}{ Denemc gruplar } & \multirow{3}{*}{$\mathrm{F}$} \\
\hline & \multicolumn{3}{|c|}{ Kontrol grubu } & \multicolumn{3}{|c|}{1} & \multicolumn{3}{|c|}{2} & \multicolumn{3}{|c|}{3} & \\
\hline & 11 & $x$ & $S x$ & $\mathrm{n}$ & $x$ & Sx & $\mathrm{n}$ & $\mathrm{x}$ & $S x$ & $\mathrm{n}$ & $x$ & $S x$ & \\
\hline Baş̧angı̧̧ & 82 & 7.16 & 0.06 & 82 & 7.12 & 0.07 & 82 & 7.19 & 0.07 & 82 & 7.09 & 0.07 & 0.48 \\
\hline 1 & 80 & $22.51 \mathrm{~b}$ & 0.45 & 81 & $21.77 \mathrm{~b}$ & 0.40 & 80 & $25.26 \mathrm{a}$ & 0.47 & 79 & $24.63 \mathrm{a}$ & (1.50) & $13.47^{* *: *}$ \\
\hline 2 & 81 & $60.38 \mathrm{ab}$ & 1.01 & 81 & $58.25 \mathrm{~b}$ & 0.90 & 80 & $62.22 \mathrm{a}$ & 0.94 & 79 & $58.83 b$ & 1.28 & $2.93 *$ \\
\hline 3 & 80 & $100.62 a b$ & 1.37 & 78 & $97.05 b$ & 1.26 & 78 & $101.65 \mathrm{a}$ & 1.08 & 78 & $97.09 \mathrm{~b}$ & 1.29 & $3.59^{*}$ \\
\hline 4 & 76 & $131.86 \mathrm{a}$ & 1.66 & 77 & $125.37 \mathrm{c}$ & 1.67 & 77 & $129.92 \mathrm{ab}$ & 1.29 & 77 & $127.40 \mathrm{bc}$ & 1.39 & $3.53 *$ \\
\hline 5 & 76 & 164.02 & 2.67 & 76 & $159 .(19$ & 2.33 & 77 & 160.66 & 2.11 & 76 & 157.81 & 1.93 & 1.39 \\
\hline
\end{tabular}

Aynı sırada farklı harf taşıyan ortalamalar arasındaki farklar öncmlidir, ${ }^{*} p<0 .\left(05,{ }^{* *} p<0.01\right.$.

Tablo 3. Gruplarda haftalık canlı ağırlık artı̧̧ı, yem tüketimi ve yemden yararlanma oranına (kg yem/kg canlı a ă̊rlık artışı) ait ortalatma degerler.

Table 3. Mcan weekly live weight gain, feed consumption and feed efficiency (kg fecd/kg live weight gain) values of groups.

\begin{tabular}{|c|c|c|c|c|c|}
\hline \multirow[t]{2}{*}{ Hafta } & \multirow[t]{2}{*}{ Kriterler } & \multirow[t]{2}{*}{ Kontrol grubu } & \multicolumn{3}{|c|}{$\mathrm{Deneme} \quad \mathrm{gruplar}$} \\
\hline & & & 1 & 2 & 3 \\
\hline \multirow[t]{3}{*}{1} & Yem tiiketimi, g/civciv & 23.15 & 27.77 & 23.21 & 25.17 \\
\hline & Canlı ağırlık artışı g/civciv & 15.35 & 14.64 & 18.07 & 17.55 \\
\hline & Yemden yararlanma oran & 1.53 & 1.90 & 1.29 & 1.44 \\
\hline \multirow[t]{3}{*}{2} & Y:sm tiiketimi, g/civciv & 54.86 & 49.30 & 53.12 & 50.24 \\
\hline & Canl! ağırlık artışı, g/civciv & 37.84 & 36.46 & 36.96 & 34.20 \\
\hline & Yemden yararlanma oranı & 1.45 & 1.35 & 1.44 & 1.47 \\
\hline \multirow[t]{3}{*}{3} & Yom tïketimi, g/civciv & 104.81 & 110.10 & 104.56 & 102.07 \\
\hline & Canlı ağırlık artışı, g/civciv & 40.26 & 38.82 & 39.42 & 38.28 \\
\hline & Yomden yararlanma oran & 2.60 & 2.84 & 2.65 & 2.67 \\
\hline \multirow[t]{3}{*}{4} & Yom tïketimi. g/civciv & 141.48 & 132.01 & 129.89 & 129.14 \\
\hline & Cänlı ağırık artışı, g/civciv & 31.28 & 28.37 & 28.28 & 30.28 \\
\hline & Yemden yararlanma oranı & 4.54 & 4.65 & 4.59 & 4.27 \\
\hline \multirow[t]{3}{*}{5} & Yem tiikctimi, g/civciv & 156.45 & 164.20 & 162.84 & 1.59 .92 \\
\hline & Catnlı atğrlık artışı, g/civciv & 32.16 & 33.69 & 30.72 & 30.41 \\
\hline & Yemden yararlanma oranı & 4.86 & 4.91 & 5.30 & 5.27 \\
\hline \multirow[t]{3}{*}{$0-5$} & Yem tiiketimi, g/civciv & 480.76 & 483.37 & 473.62 & 466.53 \\
\hline & Canlı ağırlık artışı, g/civciv & 156.90 & 151.99 & 153.45 & 150.73 \\
\hline & Yemden yararlanma oranı & 3.06 & 3.18 & 3.09 & 3.10 \\
\hline
\end{tabular}


Tablo 4. Grupların ortalama karkass ağırlıkları ve randımanlan Tablc 4. Mcan carcass weight and yicld of experimental groups.

\begin{tabular}{|c|c|c|c|c|c|c|c|c|c|}
\hline \multirow{3}{*}{ Kriterler } & & & \multicolumn{6}{|c|}{ Deneme gruplart } & \multirow{3}{*}{$\mathrm{F}$} \\
\hline & \multicolumn{2}{|c|}{ Kontrol grubu } & \multicolumn{2}{|c|}{1} & \multicolumn{2}{|c|}{2} & \multicolumn{2}{|c|}{3} & \\
\hline & $x$ & Sx & $x$ & Sx & $x$ & $S x$ & $x$ & Sx & \\
\hline Camlı a arorlık, g & 162.55 & 3.23 & 167.33 & 6.16 & 165.39 & 6.10 & 160.96 & 4.70 & 0.30 \\
\hline Karkals a agrtlığ & 111.30 & 1.40 & 115.52 & 2.75 & 116.08 & 3.27 & 111.61 & 2.47 & 0.97 \\
\hline Karkas randmant, \% & 68.64 & 1.00 & 69.47 & 1.35 & 70.44 & 0.80 & 69.53 & 0.87 & 0.51 \\
\hline
\end{tabular}

Gruplar arasindaki fark önemsizdir $(p>0.05)$.

Tatblo 5. Kan serumunda totial protein ve total lipid de gerleri $(\mathrm{g} / \mathrm{l})$

Table 5. Total protein and total lipid values of blood serum $(\mathrm{g} / \mathrm{l})$.

\begin{tabular}{|c|c|c|c|c|c|c|c|c|c|}
\hline \multirow{3}{*}{ Kritcrler } & & & \multicolumn{6}{|c|}{ Deneme gruplar } & \multirow{3}{*}{ F: } \\
\hline & \multicolumn{2}{|c|}{ Kontrol grubu } & \multicolumn{2}{|c|}{1} & \multicolumn{2}{|c|}{2} & \multicolumn{2}{|c|}{3} & \\
\hline & $x$ & Sx & $x$ & Sx & $x$ & Sx & $x$ & Sx & \\
\hline Total protcin & 51.95 & 3.05 & 50.22 & 3.11 & 46.36 & 2.83 & 47.78 & 1.67 & 0.83 \\
\hline Tolal lipid & 12.71 & 0.33 & 12.42 & 0.37 & 11.47 & 0.42 & 11.83 & 03.31 & 2.45 \\
\hline
\end{tabular}

Gruplar arasindaki fark onemsizdir $(p>0.05)$.

protein ve total lipid değerleri ise Tablo 5'de gösterilmektedir. Araşurma süresince kontrol grubunda 6 (\%7.32), deneme gruplarında ise sirasiyla 6 (\%7.32), 5 (\%6.10) ve $6(\% 7.32)$ olmak üzere toplam 23 hayvan ölmuiştür. Ölüm oranı bakımından gruplar arasındaki farkın önemli olmadığ $\left(\chi^{2}=0.14 ; p>0.05\right)$ gözlenmiştir. Gruplarda bulunan erkek ve dişi bıldırcın sayısında önemli bir larklılık olmadığı da $\left(\chi^{2}=0.30 ; p>0.05\right)$ tespit edilmiştir.

\section{Tartışma ve Sonuç}

Arpa ve buğday ağırlıklı bıldırcın rasyonlarında cnzim ve avoparsinin ayrı ayrı ya da birlikte kullanılması, Jap̧on bıldırcınlarında beş haftalık araştırma sonunda canlı ağırlık bakımından istatistik açıdan bir farklılık oluşıurmamıştır. Araşırma sonuçları bazı araştırıcıların kanath rasyonlanna antibiyotik $(17,20,27,43)$, enzim (38) ve cnzinı+antibiyotik (4.3) ilavesinden canlı ağırlığın etkilenmediğini bildiren bulguları ile uyum göstermektedir. Buna karşılık, broyler rasyonlannda Wiedmer ve Thomann (44) 7.5 ve 10 ppm, Cengiz (12) 10 ve 15 ppm avoparsin hulunmasının canlı ağırlığı istatistik açıdan önemli derccede arturdiğm ( $\mathrm{p}<0.05)$ bildirmişlerdir. $\mathrm{Bu}$ araştırna bulgularına t.1t olarak Karakuş (24) roxazym-G ve roxazym-G+avoparsin tïketen grupların canlı ağılığının kontrol grubundan istatistik açıdan önemli derecede yüksck $(p<0.01)$ olduğunu gözlemiştir. Ayrıca, yapılan araşurmada elde edilen bulgular broyler rasyonlarına katılan enzimlerin canlı ağırlığı olunlu yönde etkilediğini bildiren araşturma bulgularıyla $(8,16,32,37,45)$ benzerlik göstcrmemekıcdir.

Araşturma süresince rasyonunda avoparsin, enzim ve avoparsin+cnzim bulunan gruplann canlı ağırlı ar- uşının kontrol grubunun ağırlık arışından sırasıyliı $\% 3.13,2.20$ ve 3.93 düzeyinde daha dỉşiik olduğu görülmektedir. Bazıı çalışmalarda kanatlı rasyonlarına enzim $(7,23,24,33,45)$, antibiyotik $(2.32,44)$ ve enzimtantibiyotik $(2,14,24,43,46)$ ilavesinin canlı ağılık arışı üzerine olumlu etkisi olduğu bildirilmiştir. Buna karşılık. bazı araşturıcılar broyler rasyonlarında kullamılan enzin (4.13) ve antibiyotiklerin $(24,26,29,44)$ canlı ağırlık arlış tizerinde önemli bir etkisinin olmadığ Arpa-buğday ağırlıklı bıldırcın karma yenlerinde enzim $(38,46)$, antibiyotik (46), enzim +antibiyotik (46) kullanımının canlı ağırlık artışında istatistik bakımından bir farklılık yaratmadığı bildirilmiştir.

Araştırmada bıldırcın rasyonlarına enzim ve avoparsin+enzim ilavesi 35 günlïk yem tïkelimini kontrol grubuna göre srrassyla \%1.49 ve 2.96 diizeyinde azaltmışur. Rasyonunda sadece avoparsin bulınian grubun yem tüketimi ise kontrol grubuna göre \%0.54 dï\%yinde artmışır. Bazı araştırıcılar rasyonlara antibiyotik (10,12, 16,43), enzim (7,9,21.25,36) enzim+antibiyolik (16.46) ilavesinin yem tüketimini etkilemedig̨ni bildirmişlerdir. Buna karşılık, bazı araştırıcılar da kanatlı rasyonlarında antibiyotik (19,32), enzim $(8,16,22.34)$ kullanilmasmm yem tüketimini arturdığını kayclotmişlerdir. Iki haftulık bildırcinlarla yapılan bir araştırnada (32) rasyonlarda bulunan $20 \mathrm{ppm}$ düzeyindeki avoparsinin yem tiiketimini

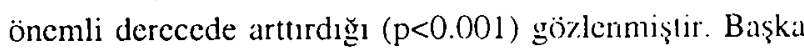
bir araşurmada (24) ise broyler rasyonlarma avoparsin, roxazym-G, roxazym-G+avoparsin ilavesinin yem tiiketimini sırasıyla \%4.48, 6.57 ve 5.73 diuzeyinde azalttğ kaydedilmiştir. 
Bıldırcinlarla yapılan araşırma süresince bir $\mathrm{kg}$ canh ağırlık artışı için tiiketilen yem miktarı kontrol ve deneme gruplarnda sirasiyla $3.06,3.18,3.09$ ve $3.10 \mathrm{~kg}$ olarak hesaplanmıştır. Rasyonlara avoparsin, enzim ve avoparsin+enzim ilavesi bir kg canlı ağırlık artışı için tüketilen yem miktarınm kontrol grubundan sırasıyla \%3.92, 0.98 ve 1.31 dizeyinde daha fazla olmasina yol açmışur. Buna karşılık. Karakuş (24), broylerler ile yaplığ 42 günlük araşurmada rasyonlara avoparsin, ro$x a / y m-G$. avoparsin+roxazym-G ilavesinin toplam yem liikeliminin kontrol grubuna göre sirasıyla bir kg canlı ağırlık arışı için \%7.6, 17.4 ve 18.8 daha az olmasına yol açlığımı kaydetmiştir. Aynı şekilde, yemlere enzin $(21.22 .30,34,36)$ veya antibiyotik $(14,16,20,29,44) \mathrm{ka}-$ ulmasının yemden yararlanma oranını olumlu yönde etkilediği bildirilmiştir. Bazı araştırıcılar $(2,3,12,17)$ rasyonlara antibiyotik ilavesinin. kümes hijyenine dikkat edildiği yetistirme koşullarmda kanatlilarda besi performansm etkilemediğini rapor etmişlerdir. Enzim ilavesinin yenden yararlanma oranını ctkilemediğini bildiren bulgular da $(7,32)$ bulunmaktadır.

Bazı çalışmalarda broyler rasyonlarında enzim ve antibiyoliğin birlikle kullanılmasının yemden yararlanma oranın olumlu yönde ctkilediği $(2,14)$ bildirilirken Elwinger ve Teglör (16) uygulamann yemden yararlanma oranında farklılık yaratmadığını kaydetmişlerdir.

Yapılan araştırmada bıldıreın rasyonlarına enzim ve/ veya antibiyolik ilavesi, soğuk karkas ağırlığı ve soğuk karkas randınıanı hakımından istatistik açıdan farklılığa neden olmamuşur.

Araştırma sonuçlarına benzer olarak Vukic-Vranjes ve Wenk (43) 10 ppm. Cengiz. (12) 10 ve 15 ppm avoparsinin broylerlerde soğuk karkas randımanını, $\Lambda$ lp ve ark. (3) 15 ppm avoparsinin sicak karkas randımanını etkilemediğini kaydetmişlerdir. Çalışma bulgulan arpabuğday ağırlık:lı rasyonlara enzin ilavesinin karkas randıman değerlerini etkilemediğini bildiren literatürlerle $(15.16,25,45.46)$ uyum içerisindedir. Buna karşlık, bulgular bazı araşurıciların rasyonlara ilave edilen antibiyotiğin $(16,28)$ ve enzimin (25) kanatlılarda karkas randımanmı artlurdığı şeklindeki bildirişlerine uymamaktadir

Gruplarda ölüm oran sırasıyla \%7.32, 7.32, 6.10 ve 7.32 olarak hesaplanıp gruplar arasındaki farkın istatistik açıdan önemli olmadığı gözlenniştir. Araştırma sonuçları olün oranmn antibiyotik $(12,17,24,45)$, enzim (24) veya antibiyotik+enzim (24) kullanımından etkilenmediğini bildiren bazı araştırıcıların bulguları ile uyum içerisindedir

Kan scrurnu total protein ve total lipid düzcyleri, bıldırcınlarla yapılan bazı araştırmalarda $(46,47)$ elde edilen değerler arasında bulunmuştur. Bıldırcın rasyonlarında enzim ve avoparsinin ayrı ayrı ya da birlikte kullanılması kan serumu total protein ve total lipid hakmmndan istatistik açıdan bir farkhılık oluşırmanıştır. Araşurmada clde edilen değerler Karakuş (24) ve Cengiz (12)'in bulgulan ile benzerlik göstermektedir. Yapılan araştırma bulgularına zil olarak Pettersson ve ark. (35). serum lipid düzeylerinin, Aidukonene ve Kiguolene (1) ile Sirvidis ve Mishhinene (39), serum total protein diizeylerinin ras yonlara enzim ilavesi ile yiikseldiğini bildirmişlerdir

Araşurma bulgularının bazı literatuir bildirişlerinden farklılık göstermesi. araştırmalardaki hijyen koşullarının farklı olmasına, hayvanların bulunduğg ortama, hayvanlann sağlık durumuna, rasyonun yapısı ve besin madde bileşini gibi faktörlere bağlı olabilir.

Sonuç olarak, hayvanlarda stresin yaraulımadığı ve kümeste hijyen koşullarının sağlandığ ortamlarda bıldircin rasyonlarma enzim ve/veya avoparsin ilavesinin besi performansı üzerinde önemli bir etki olışturmayacağı kanısına varılmışı̆

\section{Kaynaklar}

1. Aidukonene B, Kiguolene V (1988): Effect of enzyme preparations, Lysozyme G.3.x and Protosubrilin G3.x on physiological and biochemical values of blond in broiler chickens. Nauch tr vuzov Lit SSR. Biologiya. 26. 39-44.

2. Allen CM, Bedford MR, McCracken K.J (1945): A synergistic response to enzime and antibiotic supplementation of wheat-based diets for broilers. $10^{\text {th }}$ Earopean Symposium on Poultry Nutrition. 15-19 October 1995. Antalya. World's Poultry Sci Assoc Proccedings. 369-370).

3. Alp M, Kahraman $\mathbf{R}$, Kocabağlı N, Eren $M$, Şenel HS (1993): Lactiferm-L.5 ve haze amtihyoriklerin brovler per-

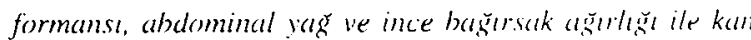
kolesteroliune etkileri. Istanbul Üniv Vet Fak Derg. 19. 145-157.

4. Annison G, Hughes R.J, Choct $\mathbf{M}$ (1996): leffects of enzyone supplementation on the nutritive value of dehulled lupins. Brit Poultry Sci, 37, 157-172.

5. AOAC (1984): Official Methods of Analyses of the As. sociation of Official Analytical Chemists. $14^{\text {th }} \mathrm{ccl}$. Inc. Arlington, Virginia.

6. Bedford MR, Classen HL, (1992): Reduction of intestinal viscosing through manipulation of dietary ye and pentosanase concentrations. is effected through changes in carbohydrate composition of the intestinal agueous phase and results in improved growth rate and food conversion of ficiency of broiler chicks. J Nutr. 122. 560)-569.

7. Broz J, Frigg M (1986): Effects of cellulolitic enzyme prosdacts on the feeding value of various broiler diets. Arch Geflügclk. 50, 104-110.

8. Broz J, Frigg M (1990): Influence of Trichoderma viride enzyme complex on nutritive value of barley and oats for broiler chickens. Arch Gefliigelk, 54, 34-37. 
9. Broz J, Ordale P, Perrin-Voltz AH (1994): Effect of Trichoderma viride enzyme complex on performance of broiler chicken.s receiving pelleted diets. Arch Geflügclk, 58, 182185.

11). Buresh RE, Miles RD, Harms RH (1985): Influence of virginiamycin on phosphorus utilization by broiler chicks. Poultry Sci, 64, 757-758.

11. Cave NA, Wood PJ, Burrows VD (1990): The nutritive value of naked oats for broiler chicks as affected by dietary additions of oat gum. enzyme. antihiotic, hile sals and fatsoluble vitumins. Can J Anim Sci. 70, 623-633.

12. Cengiz Ü (1999): Broyler Rasyonlarmda Avoparsin Kullamumı. Doktora Tezi. Ankara Üniversitesi Saglık Bilimleri Enstitiisii. Hayvan Besleme ve Beslenme Hastalıkları Anabilim Dalı, Ankara.

13. Classen HL, Campbell GL, Grootwassink DW (1988): Inproved feeding value of saskatchewan-grown barley for broiler chickens with dietary enzyme supplementation. Can J Anim Sci. 68. 1253-1259.

14. Çalışkaner S, Ceylan N, Günal M (1995): Çavdar i̧̧eren brovler rasyonlarma ilave edilen antibiyotik ve enzimin besi performansı ve bazı bağırsak parametrelerine etkisi. YUTAV 95 Lfuslararası Tavukçuluk Fuarı ve Konferansı. 24-27 Mayıs 1995, 1stanbul. Bildiriler, 145-161

15. Çiftçi İ, Yenice E, Gökçeyrek D, Öztürk E (1997): Arpa 'e buğday içeren tavuk yemlerinde enzim kullanımı. YLTAV 97 Uluslararası Tavukçuluk Fuları ve Konferansı, 14-17 Mayıs 1997. Istanbul. Bildiriler, 199-211:

16. Elwinger K, Teglöf B (1991): Performance of broiler chickens as influenced by a dietary enzyme complex with and without antibiotic supplementation. Arch Geflugelk, 55. 69-73

17. Erdoğan Z (1999): Broyler rasyonlarunda antibiyotik ve probiyotik kullanlınası. Lalahan Hay Araşt Enst Derg, 39. 57-69.

18. Ersoy E, Bayşu N (1981): Prutik Biyokimya. AÜ Vet Fak Yaymlar: 372, Ankara Üniversitesi Basımevi, Ankara.

19. Fairley C, Chanter DO, McAllister A, Roberts NL, Smith H (1985): Effect of avoparcin interaction with anticoccidial compounds on the growth and carcasse composition of broilers. Brit Poultry Sci, 26, 465-471.

20. Fethicre R, Miles RD (1987): Intestinal tract weight of chicks fed an antibiotic and probiotic. Nutr Rep Intern, 36, 1305-1309.

21. Francesch M, Perez-Vendrell, AM, Esteve-Garcia F, Brufau J (1994): Effect of cultivar, pelleting and enzyme addition on nutritive value of barley in poultry diets. Brit Poultry Sci. 35, 259-272.

22. Graham H, Pettersson D (1992): A note on the effect of a $\beta$-slucanase and multi-enzyme on production in broiler chicks fed a harley-based diet. Swedish J Agric Res, 22. 39-42

23. Jeroch H, Gruzauskas R, Volker L (1992): The effect of varien on the feeding value of barley for broiler chickens and efficiency of enzyme preparation containing $\beta$ slucanase. XIX. World's Poultry Congress. Amsterdam. The Netherlands. 20-24 Scptember 1992, Proceedings.

24. Karakuş E (1999): Broyler Rasyonlarına Katılan Enzim ve Avoparsinin Besi Performansma Etkileri. Doktora Tezi.
Ankara Üniversitesi Sał̆lı Bilimleri Enstitisisi. Hayvan Besleme ve Beslenme Hastalıkları Anabilim Dalı. Ankara.

25. Kardeş S (1996): Arpa ve Buğday' Ağırlikl Rasyonlara Kattlan $\beta$-glucanaz ve Arabinoksilanaz Enzimlerinin Ellik Piliçlerin Performanslar ile Bazı Kan Parametrelerine Etkileri. Doktora Tezi. Uludağ Üniversitesi Sağlık Bilimleri Enstituisui, Hayvan Besleme ve Beslenme Histadıkları Aniabilim Dalı, Bursa.

26. Krinke AL, Jamroz D (1996): leffect of feed antibiotic avoparcine on organ morphology in broiler chickens. Poultry Sci. 75, 705-7!0).

27. Lee SJ, Kim SS, Suh OS, Na JC, Lee SH, Chung SB (1993): Effect of dietary antihiotics and probiotics on the performance of broiler. J Agric Sci. 35. 539-545.

28. Leeson S (1984): Growth and carcass characteristics of broiler chickens fed virginiamycin. Nutr Rep Intern. 29. 1383-1389.

29. Leeson S, Summers JD, Ferguson AE (1980): Efficaty of avoparcin as a growth promoter for broiler chickens. Can J Anim Sci, 60, 275-279.

30. Marquardt RR, Boros D, Guenter W, Crow G (1994): The nutritive value of barley; rye, wheat and corn for young chicks as affected by use of a Trichoderma reesei enzyme preparations. Anim Fecd Sci Tech. 45, 363-378

31. Marquardt RR, Ward AT, Misir R (1979): The retention of nutrients by chicks fed rye diets supplemented with amino acids and penicillin. Poultry Sci, 58, 631-640).

32. Okan F, Kutlu HR, Canogulları S, Baykal 1 (1995): Effect of antibiotics supplementation to the diet on fattenin's performance of Japanese quail. $10^{\text {th }}$ European Symposium on Poultry Nutrition. 15.19 October 1995. Antilya. World's Poultry Science Association Proccedings. 383 . 384.

33. Petterson D, Aman P (1988): Effect of e'lnzime supplementation of diets based on wheat, ye or triticale on their productive value for broiler chickens. Anim Feed Sci Techn, 20. 313-324.

34. Pettersson D, Graham H, Aman P (1990): Enzyme supplementation of hroiler chicken diets based on cereals with endosperm cell walls rich in arabinoxylans or mixed-linked B-glucuns. Anim Prod. 51, 201-207.

35. Pettersson D, Graham H, Aman P (1992): Enzyme supplementation of low or high crude protein concemration diets for hroiler chickens. Brit Poultry Sci. 33i 399-4(14.

36. Rotter BA, Neskar M, Marquardt RR, Guenter W (1989): Effect of different enzyme preparations on the nutritional value of barley in chicken diets. Nutr Rep Intern. 39, $107-120$.

37. Salih ME, Classen HL, Camphell GL (1991): Response of chickens fed on hull less barley to dietary: B-glucanase at different ages. Anim Fecd Sci Techn. 33. 139-149.

38. Sevgili H, Özen N, Ertürk MM (1999): Arpa-bur̆da! agurllklı bildercu karma yemlerinde enzim kullamunum performansa etkileri. VIV Poultry Yutav 99. Uluslararasi Tavukçuluk Fuarı ve Konferansı. 3-6 Haziran 1999. Istanbul. Bildiriler. 617-625.

39. Sirvidis V, Mishkinene $\mathbf{M}$ (1988): Blood chemical values and meat quality of turkey hens on a diet with the enzyme 
preparation Protosubtilin G.3x. Nauch tr vuzov Lit SSR Biyologiy'd. 26. 30)-35.

40. Sümbüloğlu K, Sümbüloğlu V (1995): Biyoistatistik. 6 . Baskı. Ordemir Yayıncilık, Ankara.

41. Teitge DA, Campbell GL, Classen HL, Thacker PA (1991): Heat pretreament as a mean of improving the response to dietary pentosanase in chicks fed rye. Can J Anim Sci. 71. 51)7-513.

42. TSE (1991): Hayvan Yemleri-Metabolik (Çevrilebilir) Eneris Tarin (Kimvasal Metot). TSE No: 9610. Türk Standartlan Enstitisii, Ankara.

43. Vukic-Vranjes MV, Wenk C (1995): Influence of dietar enzyme complex on the performance of hroilers fed on diets with and without antihiotic supplementation. Brit Poultry Sci, 36, 265-275.

44. Wiedmer H, Thomann W (1978): Avoparcin in.hroiler feed. Poulliry International, May, 17, 22-24.
45. Wiedmer H, Völker L (1989): Enayme subplementution of a barley-based diet fed to broiler chickens under practical conditions. Procedings of the $7^{\text {th }}$ European Symposium on Poultry Nutrition. June 19-21. Gironal. Spain. 322-323.

46. Yalçın S, Önol AG, Şehu A, Onbaşılar i (20)(0)): Blldircin besisinde enzim. probiyotik re antibiyotik kullanulmast. Ankara Üniv Vet Fak Derg. 47. 351-360).

47. Yalçın S, Şehu A, Kaya İ (1998): Beldercun rassonlarma kanlan adi fiğ̈in (Vicia sativa L.) biivime. karkas randiman ve bazı kan parametreleri äzerine etkisi. Turk J Vel Anim Sci. 22. 37-42.

Gelis tarihi : 1J.4.2001/Kabul tarihi : 24.7.2001

Yazışma adresi:

Prof. Dr. Sakine Yalsin

Ankara Üniversitesi, Veteriner Fakültesi

Hayvan Besleme ve Beslenme Hastaliklarl Anahilim Dah. Diskapi 06110, Ankura 